\title{
Intrinsic ureteral endometriosis as a cause of unilateral obstructive uropathy
}

\author{
Ross J. Mason, MD; Abdulaziz Alamri, MD; Kaela Gusenbauer, ${ }^{3}$ Anil Kapoor, MD
}

'Department of Urology, Dalhousie University, Halifax, NS, Canada; ${ }^{2}$ Department of Surgery, King Khalid University, Abha, Saudi Arabia; ${ }^{3}$ Division of Urology, Department of Surgery, McMaster University, Hamilton, ON, Canada

Cite as: Can Urol Assoc J 2016;10(3-4):E1 19-21. http://dx.doi.org/10.5489/cuai.3191

\section{Abstract}

Endometriosis is a common gynecological condition, but involvement of the urinary tract is rare. Ureteral endometriosis can present in a nonspecific fashion, and may mimic ureteral malignancy. This case report describes a 44-year-old woman who initially presented with chronic flank pain and was found to have left-sided renal dysfunction and a distal left ureteric mass. She was eventually diagnosed with ureteral endometriosis after undergoing nephroureterectomy for what was thought to be either a ureteral fibroepithelial polyp or transitional cell carcinoma. Ureteral endometriosis should be considered in the differential diagnosis for a woman presenting with obstructive uropathy in the presence of a ureteric mass.

\section{Introduction}

Endometriosis is defined by the presence of endometrial glands and stroma outside of the normal endometrial cavity and is a common cause of morbidity among premenopausal women. ${ }^{1-3}$ The overall prevalence of endometriosis is unknown and varies widely among various groups of patients. ${ }^{1}$ It has been found in $1-7 \%$ of asymptomatic women ${ }^{1}$ and in up to $32 \%$ of woman undergoing laparoscopy for chronic pelvic pain. ${ }^{1,4}$ It most commonly affects the ovaries, cul-de-sac, and uterosacral ligaments., ${ }^{3,5}$ Ureteral endometriosis is a rare entity, occurring in approximately $0.1 \%$ of all patients with endometriosis. ${ }^{5,6}$

Pathologically, ureteral endometriosis is classified as intrinsic or extrinsic, with the latter accounting for approximately $80 \%$ of cases. ${ }^{7}$ Intrinsic ureteral endometriosis is defined by the presence of endometrial tissue in the lamina propria or tunica muscularis of the ureter, while extrinsic ureteral endometriosis involves the peri-ureteral tissue. ${ }^{3,6,8,9}$ Interestingly, it is appears to be an asymmetric disease, with more frequent involvement of the left ureter. ${ }^{2,3,6,10}$

Several challenges arise in diagnosing ureteral endometriosis preoperatively. Typical symptoms include dysuria, urin- ary frequency, flank discomfort, and hematuria - symptoms that are nonspecific and present in other, much more common conditions. ${ }^{2,3,6}$ Additionally, up to $40 \%$ of ureteral endometriosis may be asymptomatic and discovered during the course of investigation for unilateral or bilateral renal dysfunction. ${ }^{2}$ Herein, we report on a case of ureteral endometriosis in a 44-year-old woman with no previous diagnosis of endometriosis.

\section{Case report}

A 44-year-old woman presented to her family practitioner with a five-year history of recurrent left flank pain. This pain occurred cyclically with radiation to her anterior left abdomen, and there were no other associated symptoms. Her past medical history was significant for only obstructive sleep apnea and she was not taking any medications. Surgically she had undergone a tubal ligation and a cholecystectomy in the past. She also underwent diagnostic laparoscopy for mennorhagia three years prior to presentation, but no diagnosis of endometriosis had ever been made. Physical examination was unremarkable, apart from obesity and moderate left flank tenderness.

Abdominal ultrasonography was performed, which identified an atrophic left kidney with evidence of left ureteric obstruction, and she was subsequently referred to a community urologist for management. Computed tomography (CT) confirmed the presence of an atrophic left kidney with evidence of renal dysfunction. Several enlarged lymph nodes in the left retroperitoneum and left para-aortic area were also identified (Fig. 1). A followup nuclear renal scan confirmed the presence of left renal impairment, with the left kidney contributing $24 \%$ function. Ureteroscopy was performed and identified a distal ureteric stricture that was impassable with a guidewire. Retrograde pyelography revealed a filling defect in the left distal ureter proximal to the identified stricture. Urine cytology was negative for the presence of malignant cells.

Following this, she was referred to our centre for consideration of surgical management due to continuing left flank pain and the possibility of transitional cell carcinoma. 


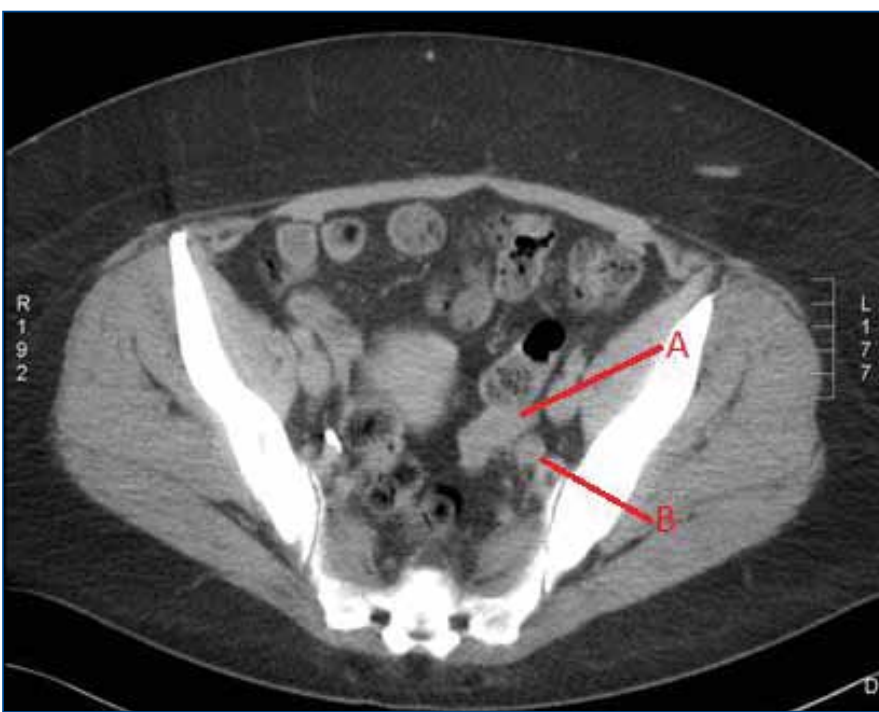

Fig. 1. Computed axial tomography (10 min delay after contrast injection) showing left-sided lympadenopathy in the retroperitoneum (A); Note the absence of contrast in the left ureter in keeping with significant renal dysfunction (B).

Repeat ureteroscopy with retrograde pyelography was performed. Again, a filling defect was identified at the level of the aortic bifurcation with marked hydroureter proximal to this (Fig. 2). Direct visualization confirmed the presence of a large, smooth, round mass that appeared to be on a stalk. It was felt that this had the appearance of a fibroepithelial polyp, but malignancy could not be excluded, especially in the presence of lymphadenopathy. She underwent laparoscopic nephrectomy followed by open ureterectomy, which revealed the presence of a bulky distal ureteric mass adherent to the vaginal wall and uterus (Fig. 3). Frozen section pathology and final pathology confirmed this mass to be consistent with endometriosis.

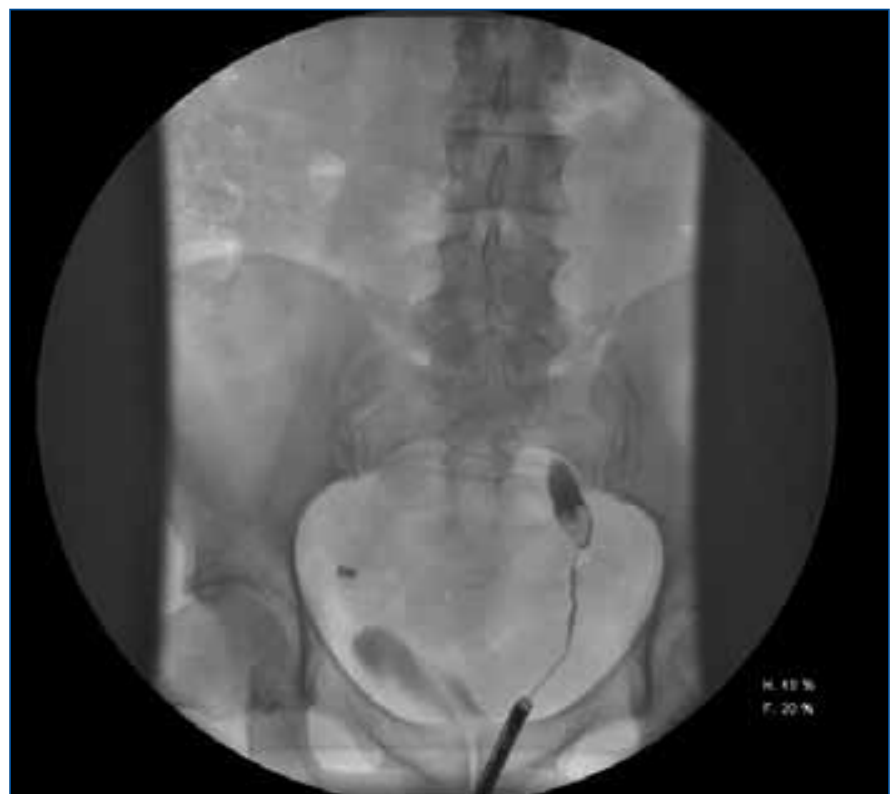

Fig. 2. Left retrograde pyelography showing a filling defect distally with evidence of hydroureter proximally.

\section{Discussion}

In this report, we present a case of ureteral endometriosis that was diagnosed post-ureterectomy in a patient with no previous diagnosis of endometriosis. A preoperative diagnosis of ureteral endometriosis is difficult to achieve, owing to nonspecific symptoms including dysuria, urinary frequency, flank discomfort, and hematuria, and cases with an absence of symptomatology. ${ }^{2,3,5,6} \mathrm{~A}$ high index of suspicion and radiological support are often necessary to obtain an early diagnosis. ${ }^{3,6}$

In the case presented above, the only symptom was that of chronic flank pain and unilateral renal dysfunction was discovered through subsequent investigations. Radiographic

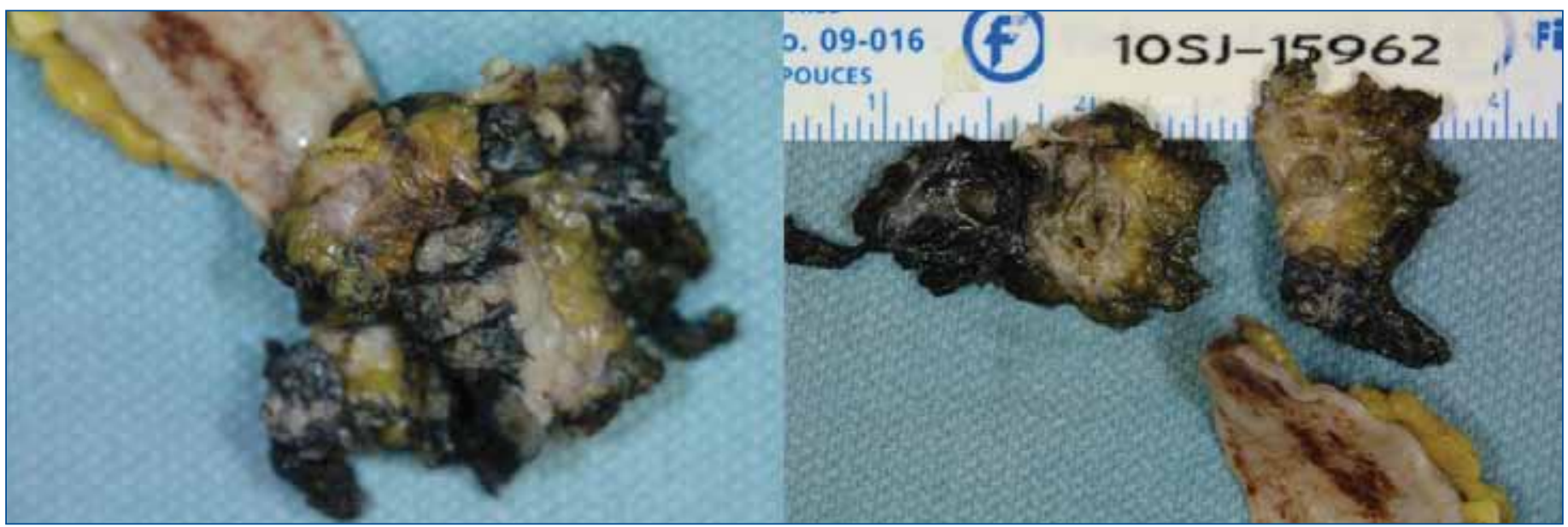

Fig. 3. Gross pathological specimen showing an endometrioma engulfing the left distal ureter. 
imaging was consistent with distal ureteric obstruction and renal dysfunction, while endoscopy confirmed the presence of a ureteral mass. Again, these findings are nonspecific and raise the concern for a possible transitional cell carcinoma. With this in mind, diagnosing ureteral endometriosis without a definitive pathological sample presents a unique challenge; this entity requires consideration when investigating a woman presenting in a similar fashion.

Owing to the rarity of ureteral endometriosis, the optimal management techniques remain unknown. For mild symptoms, conservative treatment with nonsteroidal antiinflammatory medications may provide adequate relief. ${ }^{7}$ For more significant disease, medical management with $\mathrm{GnRH}$ analogues or oral contraceptives may play a role, although hormone therapy is typically only indicated for early-stage disease. ${ }^{6,7,9}$ In approximately $25-43 \%$ of cases, ureteral endometriosis can result in ureteral obstructions, which may lead to a loss of kidney function. ${ }^{9}$ In such cases, as well as cases in which patients experience intractable symptoms, surgical intervention may be required. ${ }^{2,3,6,7,9}$

Up to $47 \%$ of patients may require a nephrectomy for either loss of kidney function, or ureteral endometriosis lesions that mimic neoplsms, most notably transitional cell carcinoma. $^{6}$

Several treatment strategies have been reported, but the choice between ureterolysis or a major urological procedure (ureterectomy, ureteroneocystotomy, or nephroureterectomy) is an area of uncertainty. ${ }^{11}$ Several cases of surgical management with ureterolysis or segmental ureteral resection have been reported. ${ }^{12,13}$ In these cases, all patients were known to have ureteral endometriosis preoperatively. In the present case, where the diagnosis was unknown and the patient remained symptomatic, nephroureterectomy was undertaken to alleviate chronic symptoms and to provide a diagnosis. In patients where the diagnosis is uncertain and irreversible renal dysfunction is present, this may be a reasonable option.

\section{Conclusion}

Ureteral endometriosis is a rare entity that may mimic a neoplastic process and can be a silent cause for renal dysfunction. ${ }^{6}$ It can present with either nonspecific symptoms or a lack of symptomatology and for these reasons, a preoperative diagnosis is difficult to achieve., ${ }^{2,3,6}$ Ureteral endometriosis should be considered in the differential diagnosis in any woman presenting with obstructive uropathy and a ureteral mass.

Competing interests: Dr. Mason, Dr. Alamri, and Ms. Gusenbauer declare no competing financial or personal interests. Dr. Kapoor is a member of the Speakers' Bureau for Pfizer and Novartis.

This paper has been peer-reviewed.

\section{References}

1. Cramer DW, Missmer SA. The epidemiology of endometriosis. Acad Sci 2002;955:11-22; discussion 34-36, 396-406. http://dx.doi.org/10.1111/i.1749-6632.2002.tb02761.x

2. Antonelli $A$, Simeone $C$, Frego $E$, et al. Surgical treatment of ureteral obstruction from endometriosis: Our experience with 13 cases. Int Urogynecol J Pelvic Floor Dysfunct 2004; 15:407-12; discussion 412. http://dx.doi.org/10.1007/s00192-004-1171-7

3. Ponticelli $C$, Graziani G, Montanari E. Ureteral endometriosis: A rare and underdiagnosed cause of kidney dysfunction. Nephron Clin Pract 2010:c89-c94. http://dx.doi.org/10.1159/000254380

4. Kresch AJ, Seifer DB, Sachs LB, et al. Laparoscopy in 100 women with chronic pelvic pain. Obstet Gynecol 1984;64:672-4.

5. Li C, Wang H, Liu H, et al Management of ureteral endometriosis: A report of 10 cases. Chin Med Sci J 2008;23:218-23. http://dx.doi.org/10.1016/S1001-9294(09)60042-0

6. Bretón SA, Carrasco AL, Gutiérrez AH, et al. Complete loss of unilateral renal function secondary to endometriosis: A report of three cases. Eur J Obstet Gynecol Reprod Biol 2013;171:132-7. http:// dx.doi.org/10.1016/i.ejogrb.2013.08.022

7. Comiter CV. Endometriosis of the urinary tract. Urol Clin North Am 2002;29:625-35.http://dx.doi. org/10.1016/S0094-0143(02)00065-4

8. Wein, Alan J, Kavoussi, Louis R, Novick, Andrew C. Partin, Alan W, Peters, Craig A. Urology, 9th ed. Campbell-Walsh Elsevier, 2010.

9. Generao SE, Keene KD, DASS. Endoscopic diagnosis and management of ureteral endometriosis. J Endourol 2005;19:1177-9. http://dx.doi.org/10.1089/end.2005.19.1177

10. Vercellini P, Pisacreta A, Pesole $A$, et al. Is ureteral endometriosis an asymmetric disease? BJOG 2000;107:559-561. http://dx.doi.org/10.1111/j.1471-0528.2000.tb13279.x

11. Camanni $M$, Delpiano $E M$, Bonino $L$, et al. Laparoscopic conservative management of ureteral endometriosis. Curr Opin Obstet Gynecol 2010;22:309-14. http://dx.doi.org/10.1097/GC0.0b013e32833beacc

12. Bosev D, Nicoll LM, Bhagan L, et al. Laparoscopic management of ureteral endometriosis: The Stanford University hospital experience with 96 consecutive cases. J Urol 2009;182:2748-52. http://dx.doi. org/10.1016/i.juro.2009.08.019

13. Smith IA, Cooper M. Management of ureteric endometriosis associated with hydronephrosis: An Australian case series of 13 patients. BMC Res Notes 2010;3:45. http://dx.doi.org/10.1186/1756-0500-3-45

Correspondence: Dr. Anil Kapoor, McMaster University, Hamilton, 0N, Canada; akapoor@mcmaster.ca 